\title{
Effects of riblets on the performances of a regional aircraft configuration in NLF conditions
}

\author{
P. Catalano, D. de Rosa ${ }^{\dagger}$ \\ CIRA Italian Aerospace Research Center, Capua (CE), 81043, Italy \\ B. Mele $\ddagger$ R. Tognaccini ${ }^{\S}$ \\ University "Federico II", Napoli, 80125, Italy \\ F. Moens , \\ Onera, The French Aerospace Lab., 92190 Meudon France
}

\begin{abstract}
The application of the riblets to a typical regional turbo-prop configuration is discussed in this paper. The effect of the riblets is modelled as a singular roughness problem by a proper boundary condition proposed by University of Napoli. The model is described and first its application to 2D flows is presented. Then a typical wing-body of a regional aircraft is considered. The configuration has been designed to have a natural laminar flow for a large extent of the wing in cruise conditions. Riblets are applied at flow specifications representative of cruise in combination with the laminar flow technology and in climb/descent conditions. The save of fuel achievable in a typical operative day of such an aircraft has been also estimated.
\end{abstract}

\section{Introduction}

Today there is renewed interest in drag reduction mechanisms. Indeed, current concern over environmental pollution is forcing manufacturers to reduce pollutant emissions not only in the industrial field but also in the transport sector. Several methods for reducing viscous drag have been studied during the last three decades. These are used to delay laminar-boundary layer transition or to modify the turbulence structures of the boundary layer. Some methods are active controls, and others are passive as they do not require any energy use. Focusing on passive devices, the natural laminar flow technology aims at extending the laminar region as much as possible. Riblets consisting of stream-wise grooved surfaces are instead good candidates to reduce friction drag in the turbulent part of the flow.

A detailed and accurate simulation of the flow around riblets requires the adoption of Direct Numerical Simulations (DNS) or Large Eddy Simulations (LES). Neverthless, complex configurations at high Reynolds numbers can still only be studied by methods based the RANS equations. However, the RANS methods cannot resolve the scales of riblets (microns in aeronautical applications) and the effect of the riblets needs to be modelled. Mele and Tognaccini ${ }^{1}$ have introduced the idea to model the effect of the riblets by a proper boundary condition at the wall such as usually done for the effect of roughness. The proposed boundary condition has been impelmented in two URANS flow solvers, the CIRA in-house developed UZEN code, and FLOWer, a code developed at DLR and used by University of Napoli. A relevant number of 2D and 3D test-cases have been carried out in order to validate and evaluate the model. ${ }^{2-5}$ This paper deals with the effect of the riblets on the performances of a real aircraft when combined with the natural flow technology. Numerical simulations have been performed at different flow conditions representative of the characteristics points of a typical mission of a regional aircraft. The main goal is to evaluate the gain achievable by the riblets over an entire mission of the aircraft.

\footnotetext{
* Research Engineer, Fluid Mechanics Unit

${ }^{\dagger}$ Research Engineer, Fluid Mechanics Unit

${ }^{\ddagger}$ Associate Researcher, Dipartimento di Ingegneria Aerospaziale

$\S$ Associate Professor, Dipartimento di Ingegneria Aerospaziale, AIAA senior member

`Applied Aerodynamics Department
} 
The paper is structured as follows. The modelling of the effect of the riblets is discussed in section II, and the results are presented in section III. First some results for 2D test cases are shown and then the application of riblets to the regional aircraft is discussed. The riblets are discussed in conjunction with the natural laminar flow technology. The weight that a new-generation turboprop aircraft could save is estimated. The conclusions are drawn in section IV.

\section{Modelling the Effect of Riblets}

It has been shown that riblets induce a displacement of the turbulence eddies with respect to the mean flow leading to a reduction of the momentum transfer to the wall with a consequent drag reduction. ${ }^{6-8}$ This mechanism is confined very near to the surface and induces a drag increase if riblets are large enough to interact directly with the turbulence structures. In practice, the effect of riblets is the shift of the origin of the velocity profile, i.e. a shift of the constant of the well known logarithmic law of wall:

$$
U^{+}=\frac{1}{\kappa_{a}} \log \left(y^{+}\right)+B-\Delta U^{+}
$$

where the superscript + specifies non-dimensional quantities obtained by using wall variables, $\kappa_{a}$ is the Kármán constant, and $B$ measures the influence of the wall on the velocity profile. Equation 1 is the same formula describing the effects of wall roughness on turbulent flows. The difference is that, in the case of roughness, $\Delta U^{+}$is usually positive returning an increase of drag, while riblets provide negative values of $\Delta U^{+}$with a reduction of the skin friction.

Tani $^{9}$ re-analyzed the classical experimental data of Nikuradse ${ }^{10}$ on turbulent flows over rough walls. He focused his attention on the transitional roughness regime that is characterized by a roughness height not large enough for a fully rough behaviour (usually the transitional roughness is defined for non-dimensional roughness height $k_{s}^{+}<50$ ). He realized that sand roughness induces a reduction of skin friction if $k_{s}^{+}$, which is often defined as roughness Reynolds number, is lower than about 6. Above this critical value, the sand roughness induces an increase of drag. Tani already noted that this behaviour is surprisingly similar to riblet effects which however induce a much greater drag reduction. On the other hand, he emphasized that, unlike riblets, sand roughness is insensitive to flow direction.

The well known wall boundary condition of Wilcox for the $k-\omega$ turbulence models family $^{11}$ is widely adopted for simulating rough walls. Wilcox derived his boundary condition from Saffman ${ }^{12}$ who first observed that, approaching the surface, the differential equations of the $\kappa-\omega$ turbulence models possess a kind of solution that returns a finite value for $\omega$ at the surface. This value can be, in principle, any value that correctly reproduces the logarithmic law of smooth, rough or grooved wall. Saffman proposed the following boundary condition for $\omega$ at the wall:

$$
\omega=\frac{\rho u_{\tau}^{2}}{\mu} \cdot S_{R}\left(k_{s}^{+}\right)=\frac{\tau_{w}}{\mu} \cdot S_{R}\left(k_{s}^{+}\right) .
$$

where $\rho$ is the density, $u_{\tau}=\sqrt{\tau_{w} / \rho}$ is the friction velocity $\left(\tau_{w}\right.$ is the wall shear stress) and $\mu$ is the dynamic viscosity. Using equation 2 and from the analysis of the experimental results of Nikuradse, Wilcox derived his condition for $S_{R}$ on rough walls:

$$
S_{R}=\left\{\begin{array}{cc}
\left(50 / k_{s}^{+}\right)^{2} & k_{s}^{+}<25, \\
100 / k_{s}^{+} & k_{s}^{+} \geqslant 25 .
\end{array}\right.
$$

Thus $\omega$ at the wall depends on $\Delta U^{+}$or equivalently on $S_{R}=S_{R}\left(\Delta U^{+}\right)$and depends on the nature of the wall. In the case of transitional roughness $S_{R}\left(\Delta U^{+}\right)$has been obtained verifying, by numerical experiments, the correct value of $S_{R}$ providing the $\Delta U^{+}$measured by Tani. A simple bell shaped function has been used to fit the new obtained values for $S_{R}$ :

$$
S_{R}=\frac{C_{1}}{\left(k_{s}^{+}-C_{2}\right)^{2 n}+C_{3}},
$$

where $C_{1}=1.666 \cdot 10^{3} ; C_{2}=3.25 ; C_{3}=0.1 ; n=1$. Equation 4 recovers for $k_{s}^{+}=0$ and $k_{s}^{+}=6.5$ the $S_{R}$ value for smooth wall. 
The same equation 4 with different coefficients and written as a function of $l_{g}^{+}=\sqrt{A_{g}^{+}}$, where $A_{g}^{+}$is the riblet non dimensional cross section area, can be used to simulate the effects of an arbitrary riblet family. In fact, following Mayoral and Jiménez, ${ }^{13} l_{g}^{+}$gives a better characterization of riblet performance than the non-dimensional riblet spacing $s^{+}$and height $h^{+}$(figure 1(a)). They found that the adoption of $l_{g}^{+}$collapse
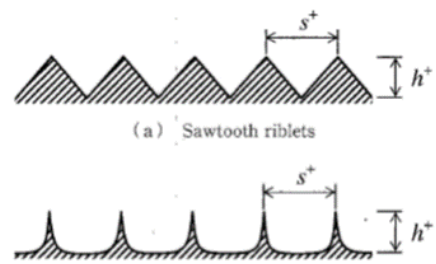

(b) Scalloped riblets
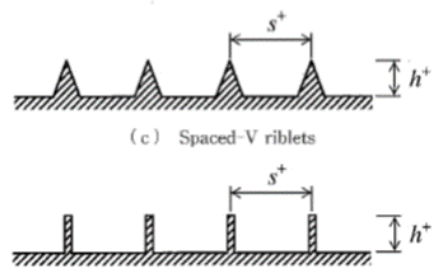

(d) Blade riblets

(a) Different shapes of riblets

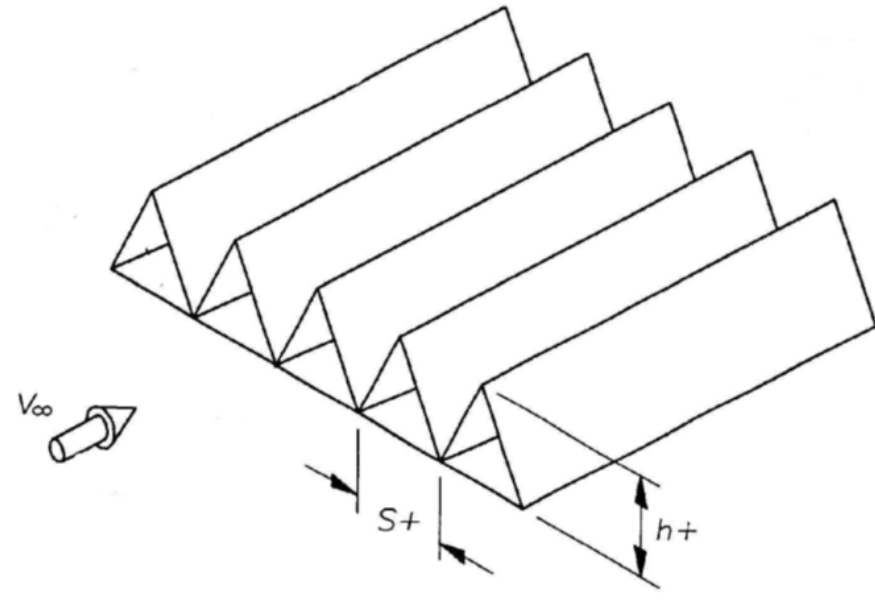

(b) "v-shape" riblets

Fig. 1: Shapes of riblets

riblet experimental data into a compact group of similar curves. Thus, in the case of riblets, equation 4 can be rewritten as:

$$
S_{R}=\frac{C_{1}}{\left(l_{g}^{+}-C_{2}\right)^{2 n}+C_{3}} .
$$

The coefficients have been obtained by numerical experiments matching the experimental data reported in: ${ }^{13}$ $C_{1}=2.5 \cdot 10^{8} ; C_{2}=10.5 ; C_{3}=1 . \cdot 10^{-3} ; n=3 . C_{2}$ is equal to the value of $l_{g}^{+}$corresponding to the maximum value of $S_{R}$, while $C_{1}$ and $C_{3}$ are related to the maximum value of $S_{R}$. In the case of the riblet family reported by Walsh, ${ }^{14}$ manufactured by $3 \mathrm{M}$ company, with a symmetric V-grooved section (figure $1(\mathrm{~b})$ ), the relation between $l_{g}^{+}, s^{+}$and $h^{+}$is $s^{+}=h^{+}=\sqrt{2} l_{g}^{+}$.

\section{Results and Discussion}

\section{A. 2D Flows}

The model described in the previous section has been applied to a series of 2D flows for purposes of validation.

The results obtained are consistent with theoretical considerations and in good agreement with the available experimental data.

\section{Flat Plate}

A flat plate at Reynolds number (based on the length of the plate $L$ ) of $1 \times 10^{6}$ has been considered. The $\kappa-\omega$ SST turbulence model has been applied. The boundary condition 5 has been applied on all the length of the plate to model the effect of the riblets.

The drag reduction, computed as percentage variation between the drag coefficient of the riblets-on configuation $C_{D}^{R}$ and the riblets-off configuration $C_{D}^{S}$, as function of $l_{g}^{+}$is shown in the left plot of figure 2. The maximum reduction is about $6 \%$ and is achieved, as expected, for $l_{g}^{+}=10.5$. The same $C_{D}$ as the smooth $\left(l_{g}^{+}=0\right.$.) configuration is obtained for $l_{g}^{+}$between 20 and 22 . Riblets with $l_{g}^{+}=22$ provide an increase of drag.

The friction coefficients obtained by applying riblets with different $l_{g}^{+}$(according to equation 5) are shown in the right plot of figure 2. The Blasius laminar and Prandtl turbulent curves are reported as a reference. 


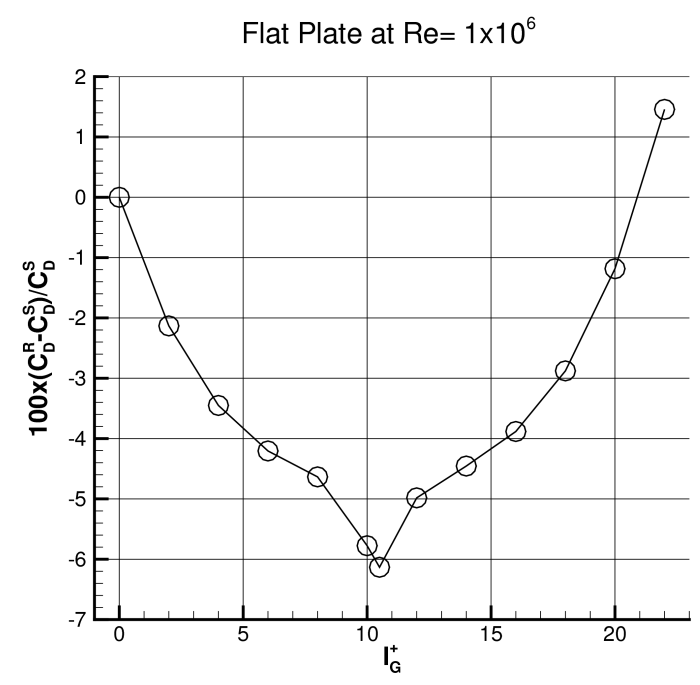

(a) $\Delta C_{D}$

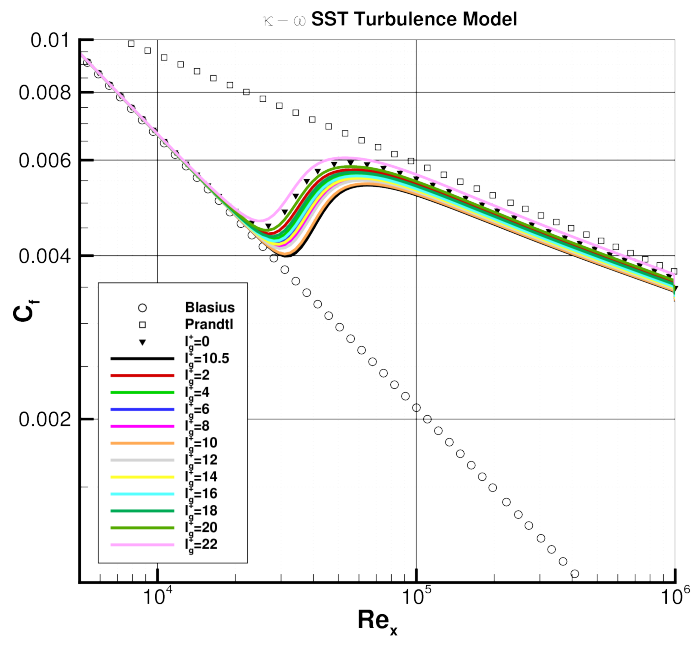

(b) $C_{f}$

Fig. 2: Flat plate at $R e=1 \times 10^{6}$ : Drag reduction and Friction coefficient

The riblets have been applied on all the surface of the plate also in the laminar part. No influence of the riblets is noted in the laminar zone of the flow but the numerical transition and the turbulent region is affected by the presence of the riblets. The transition is delayed by the riblets, and lower levels of the skin friction coefficient are attained in the turbulent part as $l_{g}^{+}$increases. The minimum level of $C_{f}$ is obtained, for $l_{g}^{+}=10.5$ which is also the case that presents the most delayed transition. The friction coefficient is always lower with respect to the clean configuration except for the riblets with $l_{g}^{+}=22$. According to the $\Delta C_{D}$ results, the riblets provide the same $C_{f}$ as the clean configuration for $20<l_{g}^{+}<22$.

As discussed in the previous chapter (equation 1), the effect of the riblets can be seen as a shift in the log-law of the velocity profiles. This can be retrieved in the achieved results. Left plot of figure 3 shows the

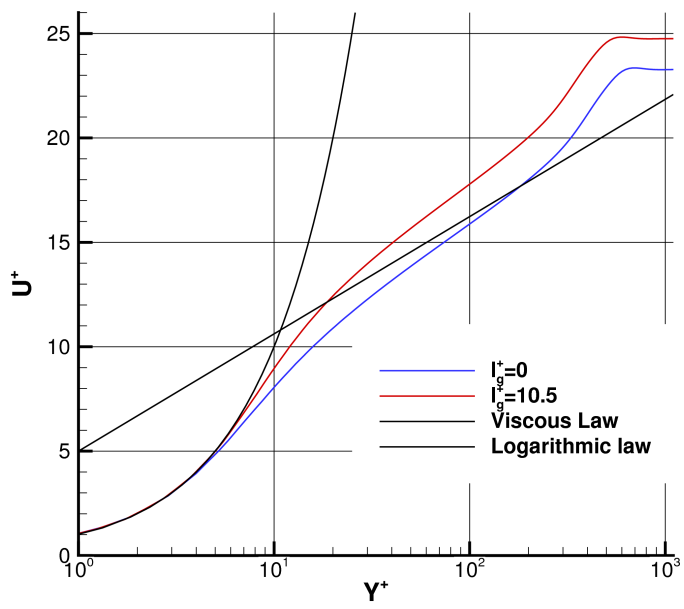

(a) Velocity profiles at $x / L=0.80$

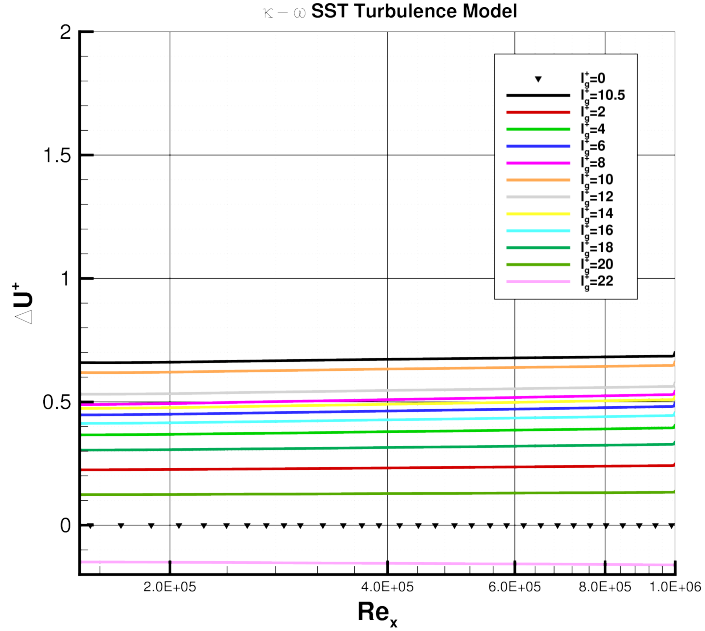

(b) $\Delta U^{+}$

Fig. 3: Flat plate at $R e=1 \times 10^{6}$ : Effect of riblets on velocity

velocity profile (in viscous units) at the station $x / L=0.80$ (i.e. $R e=0.8 \times 10^{6}$ ) for the clean configuration and for the case with $l_{g}^{+}=10.5$. It is possible to note how the profile does not change in the sub-layer where 
the theoretical curve $\left(U^{+}=y^{+}\right)$is perfectly followed, while the logarithmic part of the profile is shifted by the riblets.

The $\Delta U^{+}$due to the presence of the riblets can be estimated. In fact, at the edge of the boundary layer, the $\Delta U_{E}^{+}$is

$$
\Delta U_{E}^{+}=\left(U_{E}^{+}\right)_{R}-\left(U_{E}^{+}\right)_{S}=\left(\frac{1}{\kappa_{a}} \log \left(\delta^{+}\right)\right)_{R}-\left(\frac{1}{\kappa_{a}} \log \left(\delta^{+}\right)\right)_{S}+\Delta U^{+}
$$

where the subscripts $S$ and $R$ refer to the smooth and to the configuration equipped with riblets. By assuming that $\delta^{+}$is the same and considering that for the incompressible flow over a flat plate $U_{E} \approx U_{\infty}$ since

$$
1-\left(\frac{U_{E}}{U_{\infty}}\right)^{2}=\frac{2 \gamma}{\gamma-1} \frac{P_{E}-P_{\infty}}{\rho U_{\infty}^{2}}
$$

the velocity shift is obtained as

$$
\Delta U^{+}=\left(\sqrt{\frac{2}{C_{f}}}\right)_{R}-\left(\sqrt{\frac{2}{C_{f}}}\right)_{S}
$$

Right plot of figure 3 reports $\Delta U^{+}$for the turbulent region of the flat plate. As expected, it results to be greater than zero for all the values of $l_{g}^{+}$except for the case $l_{g}^{+}=22$. The maximum achieved values of $\Delta U^{+}$ are around 0.7 and is obtained for $l_{g}^{+}=10.5$. The increment attainable for $\Delta U^{+}$is not linear with $l_{g}^{+}$but increases around the optimal value of 10.5. It is also interesting that this velocity shift is almost constant with the Reynolds number.

\section{CASTr7 Airfoil}

The transonic flow around the CAST 7 airfoil is discussed in the following. Experimental data ${ }^{15}$ are available at Reynolds number $3 \times 10^{6}, \alpha=0^{\circ}$, and Mach numbers $0.65,0.70$, and 0.76 . Three different heights, 0.023 ,

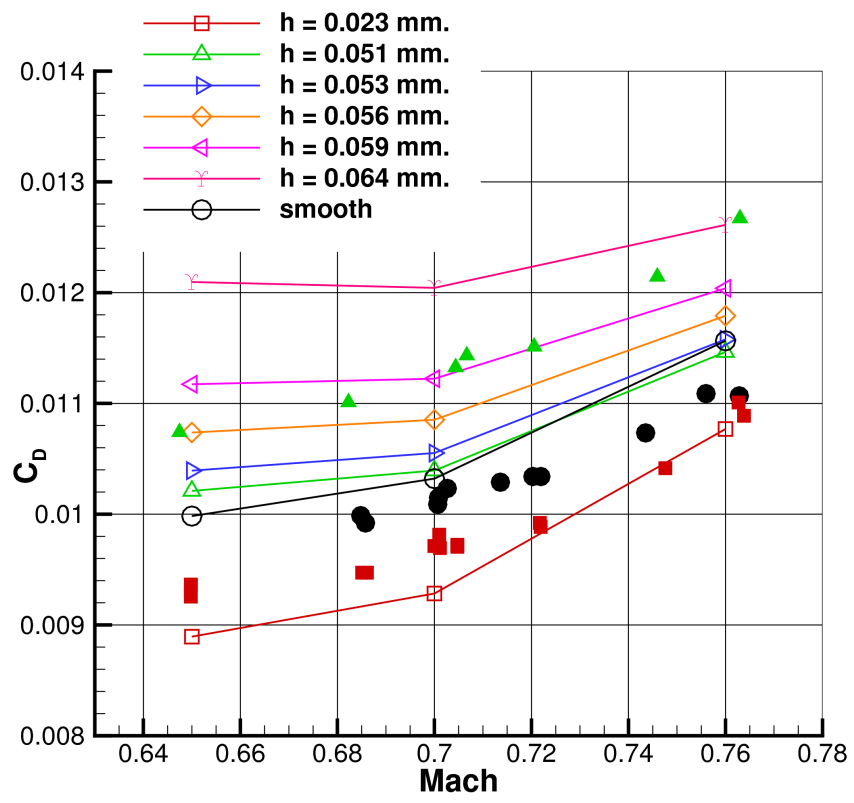

Fig. 4: CAST-7 Airfoil at Mach $=0.76, R e=3 \times 10^{6}$, and $\alpha=0$ :Drag Coefficient. Full Symbols: Experimental; Void Symbols: Numerical.

0.033 and $0.051 \mathrm{~mm}$., of "v-shape" riblets, are applied over an airfoil with a chord of $200 \mathrm{~mm}$.

The configuration has been considered with the transition imposed at $5 \%$ of the chord on both the upper and lower surfaces and the $\kappa-\omega$ SST turbulence model has been applied. The riblets are installed from the $15 \%$ of the chord. 
The drag coefficient obtained for the clean configuration and with riblets of $h=0.023 \mathrm{~mm}$. and $h=0.051$ $\mathrm{mm}$. is plotted as a function of the Mach number in figure 4. The results achieved are in a reasonable agreement with the experimental data. The behaviour with the Mach number is well predicted, but the $C_{D}$ is over-predicted for the smooth configuration (black color) and under-predicited for the riblets-on configurations with respect to the experiments (full symbols). In particular, the drag coefficient decreases at all the Mach numbers for the riblets with $h=0.023 \mathrm{~mm}$. (red color) in both experimental and numerical data. Instead the riblets with $h=0.051 \mathrm{~mm}$. present an increase of $C_{D}$ in the experiments, while the numerical simulations provide a slight decrease of drag at Mach 0.65 and 0.70 and a slight decrease at Mach 0.76. It turns out that the model and the numerics employed in the simulations require riblets somehow higher than in the experimets to achieve an increment of drag. The height of the riblets should be changed in the computations in order to get the same drag coefficient as the experiments. In particular the increase of drag presented in the experiments with riblets of $h=0.051 \mathrm{~mm}$. is obtained in the numerical simulations with a height of $0.064 \mathrm{~mm}$. at Mach $0.76, h=0.059 \mathrm{~mm}$. at Mach 0.70, and $h=0.056$ at Mach 0.65.

As an example, the friction coefficient for the smooth configuration and for the configuration with riblets of $0.023 \mathrm{~mm}$. height is presented in left plot of figure 5 . The decrease of the friction coefficient is evident

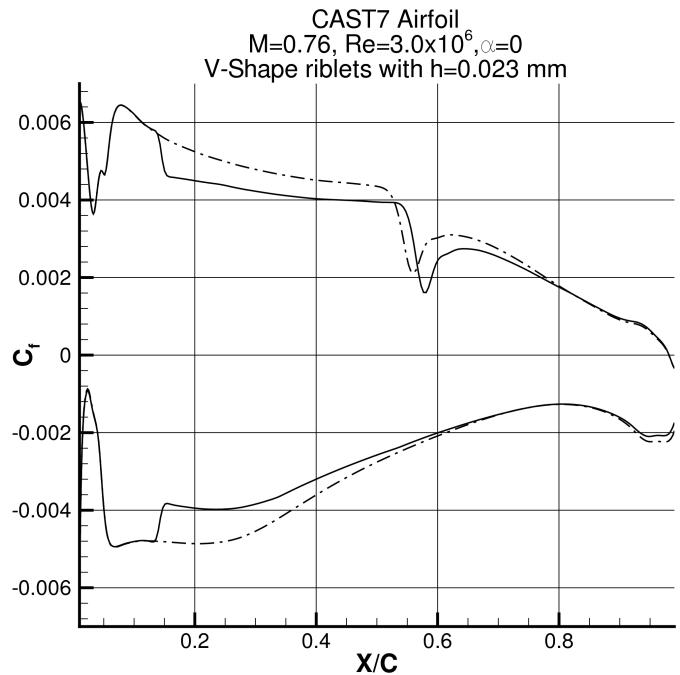

(a) $C_{f} \cdot-\cdot-$ : Riblets OFF; — : Riblets ON.

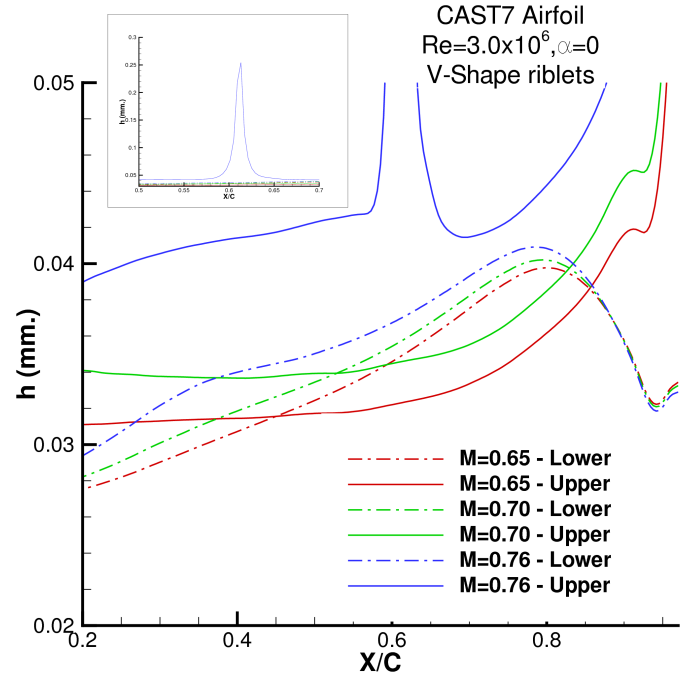

(b) Physical height corresponding to "optimal" $h^{+}$

Fig. 5: CAST-7 Airfoil at $R e=3 \times 10^{6}$, and $\alpha=0$ : Skin friction coefficient and height of the riblets

and there is also a slight effect on location and strength of the shock.

The physical height of a symmetric "v-shape" riblet can be related through to the viscous height $h^{+}$ through the following relation:

$$
h^{+}=\frac{h u_{\tau} \rho}{\mu}=\frac{h}{L_{R E F}} R e_{\infty} \sqrt{\frac{C_{F}}{2}} \sqrt{\frac{\rho}{\rho_{\infty}}} \frac{\mu_{\infty}}{\mu}
$$

The above equation 9 is useful to evaluate the physical height of "v-shape" riblets corresponding to the "optimal" $h^{+}$. This is shown in right plot of figure 5 at the three Mach numbers taken into consideration. The height increases in a not linear way with the Mach number. It also increases along the chord on both the upper and lower surface of the airfoil and presents a spike, almost doubling, close to the shock wave.

\section{DU 96-W-180 airfoil}

Chamorro et al. ${ }^{16}$ tested various riblet size and shapes provided by $3 \mathrm{M}$ company on a DU 96-W-180 airfoil. The experiments were performed in low speed conditions at a Reynolds number (based on the chord of the airfoil) of $2.2 \times 10^{6}$ and varying the lift coefficients from 0.25 to 1.14 .

The same airfoil was studied in the experiments of Sareen et al. ${ }^{17}$ They also tested various riblet size provided by 3M company at three different Reynolds numbers $1.0 \times 10^{6}, 1.5 \times 10^{6}$ and $1.85 \times 10^{6}$. 
The effect of full or partial riblet coverage on the airfoil has also been investigated in both experiments. The authors calculated, by Xfoil simulations, the transition to turbulence over the clean airfoil in its operational range and then, in the case of partial riblet coverage, the riblet film was applied starting from $40 \%$ of the airfoil chord on the upper surface and $70 \%$ on the lower surface. Sareen et al. ${ }^{17}$ also determined the experimental separation and reattachment points and reported an oil flow visualization of the detected laminar separation bubble at $\alpha=6^{\circ}$ and Reynolds number $1.5 \times 10^{6}$.

The present numerical simulations have been performed at the same flow conditions as the experiments with partial riblet coverage. All calculations have been carried out at $M_{\infty}=0.1$ and specifying the transition on the upper and lower surface at the same position reported in the experiments. In the laminar zone the production terms of the turbulence equations are set to zero; such transition treatment guarantees optimal flow prediction in case of laminar separation bubbles. ${ }^{18}$

The computed drag reduction vs. riblet height at $R e_{\infty}=1.5 \times 10^{6}$ is compared with the measurements of Sareen et al. ${ }^{17}$ in fig. 6. A satisfactory agreement is shown. The achieved maximum drag reduction is

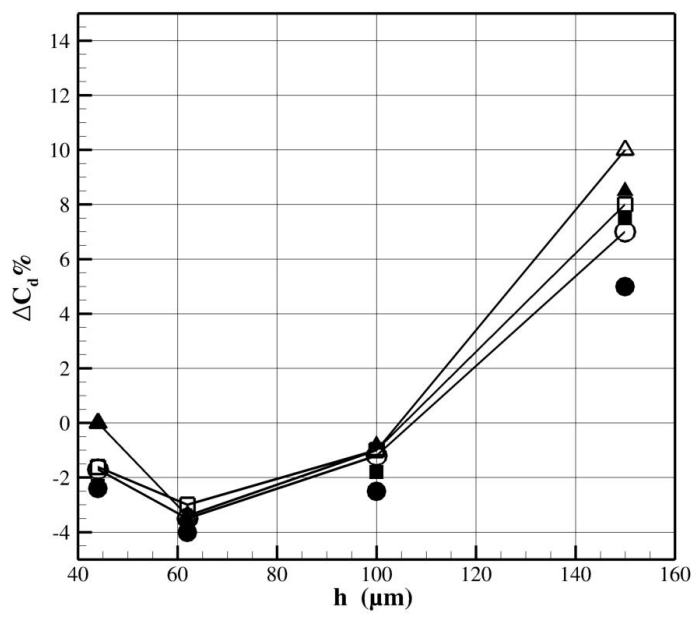

(a) $R e_{\infty}=1.5 \times 10^{6}$. $\square: C_{l}=0.75, \circ: C_{l}=0.875, \triangle: C_{l}=1$.

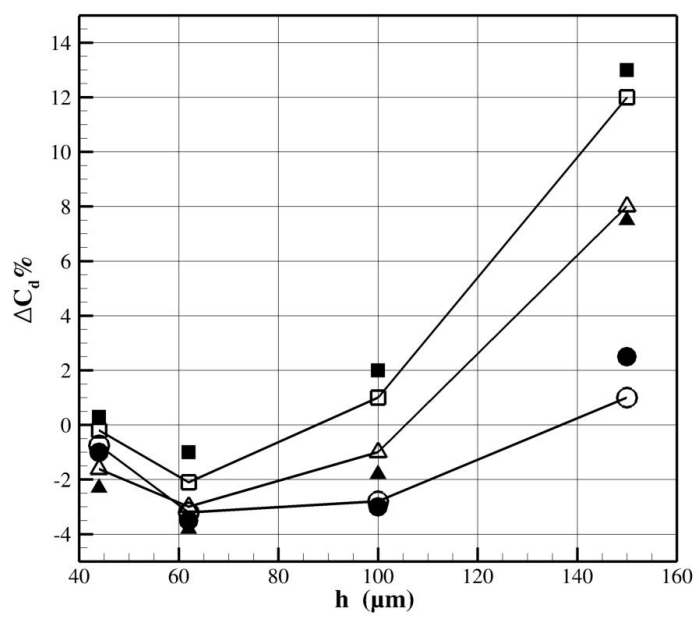

(b) $C_{l}=0.75 . \circ: R e_{\infty}=1.5 \times 10^{6}, \triangle: R e_{\infty}=1.85 \times 10^{6}, \square$ : $R e_{\infty}=1 \times 10^{6}$.

Fig. 6: DU 96-W-180 airfoil. Computed and experimental drag reduction vs. riblet height. Void symbols: Numerical, Full Symbols: experimental

$3 \%-4 \%$ and is strictly linked to the extension of the turbulent region that depends on lift coefficient. The effect of $C_{l}$ on the computed drag reduction is summarized in fig. 6a. The effect of Reynolds number is shown in Fig. 6b were the computed and measured drag reduction vs. riblet height at $C_{l}=0.75$ is shown for three different Reynolds numbers.

In fig. 7 the computed drag reduction vs. $C_{l}$ is compared with the experiments of Chamorro et al. ${ }^{16}$ performed at $R e_{\infty}=2.2 \times 10^{6}$ ( $1 \mathrm{~m}$ reference chord) with $80 \mu \mathrm{m}$ symmetric V-grooved riblets. Also in this case a satisfactory agreement between computation and experimental data is achieved.

The computed skin friction coefficients with and without riblets at $R e_{\infty}=1.5 \times 10^{6}$ and $C_{l}=0.75,0.875,1.0$ are shown in fig. 8. Detected laminar separation bubbles are clearly visible and the separation and reattachment points are in good agreement with experimental data. It is worth noting that the whole effect of riblets on skin friction coefficients is in the attached flow zone. The skin friction seems to be not influenced inside the laminar separation bubble .

\section{B. Regional Aircraft Configuration}

A wing-body configuration of a typical regional aircraft (figure 9) has been taken into consideration. ${ }^{19}$ The wing has been designed following the process used for a transonic application. ${ }^{20}$ The airfoil sections have a laminar flow in cruise conditions and the twist is optimized for the low-speed performances. A structured 


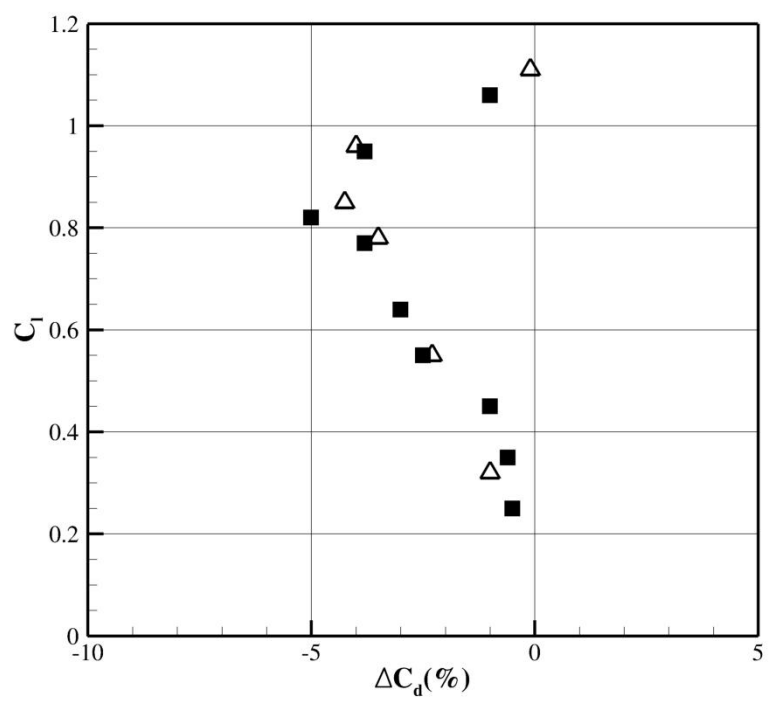

Fig. 7: DU 96-W-180 airfoil with symmetric V-grooved riblets of $h=s=80 \mu m, R e_{\infty}=2.2 \times 10^{6}$. Computed and experimental drag reduction vs. lift coefficient. $-\Delta-$ : computed, $\mathbf{\square}$ : experiments ${ }^{16}$

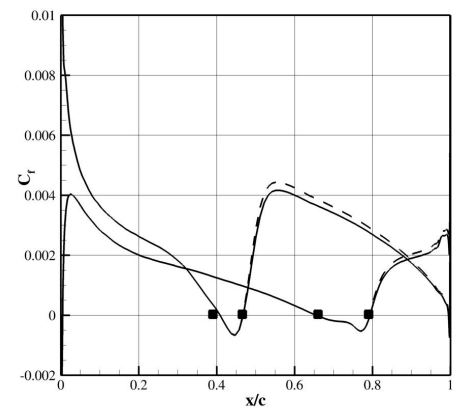

(a) $C_{l}=0.75$.

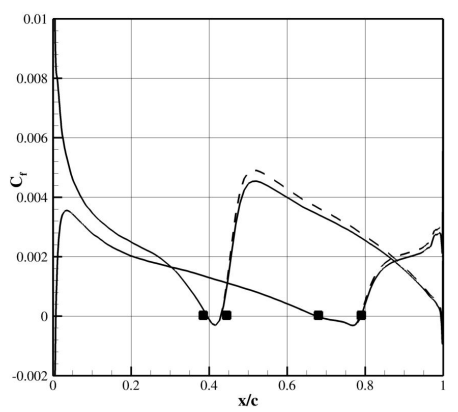

(b) $C_{l}=0.875$.

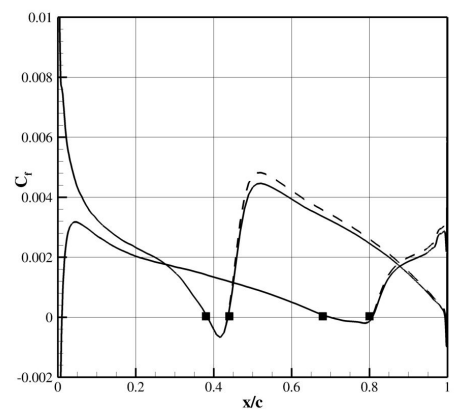

(c) $C_{l}=1.0$.

Fig. 8: DU 96-W-180 airfoil, $R e_{\infty}=1.5 \times 10^{6}$. Computed skin friction coefficients. - - : computed with riblets $h=62 \mu \mathrm{m},---$ : computed without riblets, $\mathbf{\square}$ : experimental separation and reattachment points without riblets. 


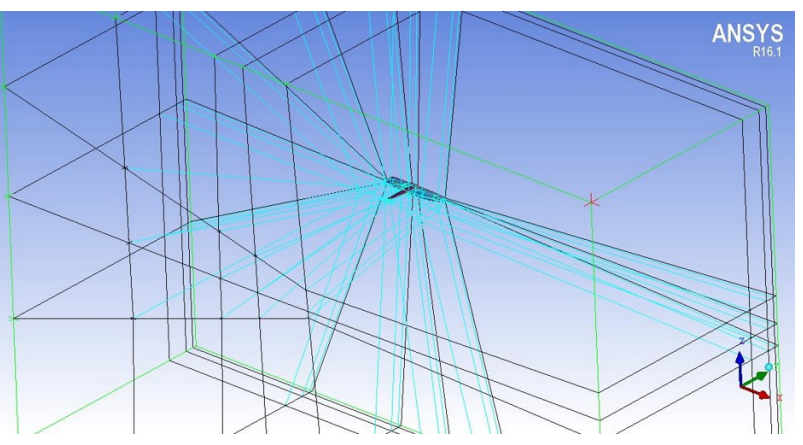

(a) Geometry

(b) Computational Grid

Fig. 9: Regional aircraft configuration

multi-block grid made of 128 blocks for a total of $23 \times 10^{6}$ million points has been generated and used to perform RANS simulations.

Different assumptions are made in order to assess the effect of the riblets in combination with a natural laminar flow (NLF). Riblets are applied with the assumption of "fully turbulent" flow and in case the flow is assumed laminar for a large part of the wing according to the NLF technology.

The riblets have been installed only on wing, only on body and on all the configuration. This kind of analysis allows to determine the zones of the configuration where the riblets are more effective.

The flow conditions investigated are representative of the mission typical of a regional aircraft. The main aim is to evaluate the gain in terms of aerodynamic drag that could be achieved by applying the riblets to such a configuration.

\section{Cruise conditions with fully turbulent assumption}

A flow condition corresponding to Mach number 0.50 and Reynolds number (based on the chord of the wing) of $3.0 \times 10^{7}$ has been considered.

The $\Delta C_{D}$ (pressure and friction contributions) with respect to the clean configuration achieved by applying riblets with $l_{g}^{+}=10.5$ is reported in figure 10. Riblets only on wing are more effective at the low incidences, while riblets only on body provide a gain in drag quite constant with $\alpha$. A combined effect is obtained when riblets are applied over all the configuration.

In percentage terms, the maximum gain in total drag evaluated as: $\Delta C_{D}=\frac{C_{D}^{R}-C_{D}^{S}}{C_{D}^{S}}$ is about $9 \%$ and decreases with the lift coefficient. The gain in friction drag evaluated as $\Delta C_{D f}=\frac{C_{D f}^{R}-C_{D f}^{S}}{C_{D f}^{S}}$ is constant with the lift coefficient and is about $11 \%$.

Figure 11 reports the skin friction distribution on the upper surface of the configuration in riblets-on and riblets-ff conditions. The riblets have been installed only on the wing. A clear decrease of the skin friction is obtained in the front part of the wing.

The right plot of figure 11 reports, as an example, the $C_{f}$ at a station located at $40 \%$ of the wing span. The gain in $C_{f}$ decreasing as $x$ increases is clearly visible. The riblets-on and clean configuration have the same levels of friction in the trailing-edge region.

The effect of applying the riblets only on the body can be appreciated in figure 12 The zone of the body where the riblets are more effective are the nose and wing-fuselage intersection.

The right plot of figure 12 shows the friction distribution along a constant-y section of the body. An effect of riblets, not visible in figure 12(a), is also present in the rear part of the fuselage.

\section{Cruise conditions with natural laminar flow technology}

The wing of the configuration has been designed to have a laminar flow for a large extent of the wing in cruise conditions. This assumption has been numerically reproduced by imposing a transition at $50 \%$ of the local chord in the outboard zone of the wing. The inboard region has been assumed turbulent because the presence of the engines prevents to keep the flow laminar (figure 13). 


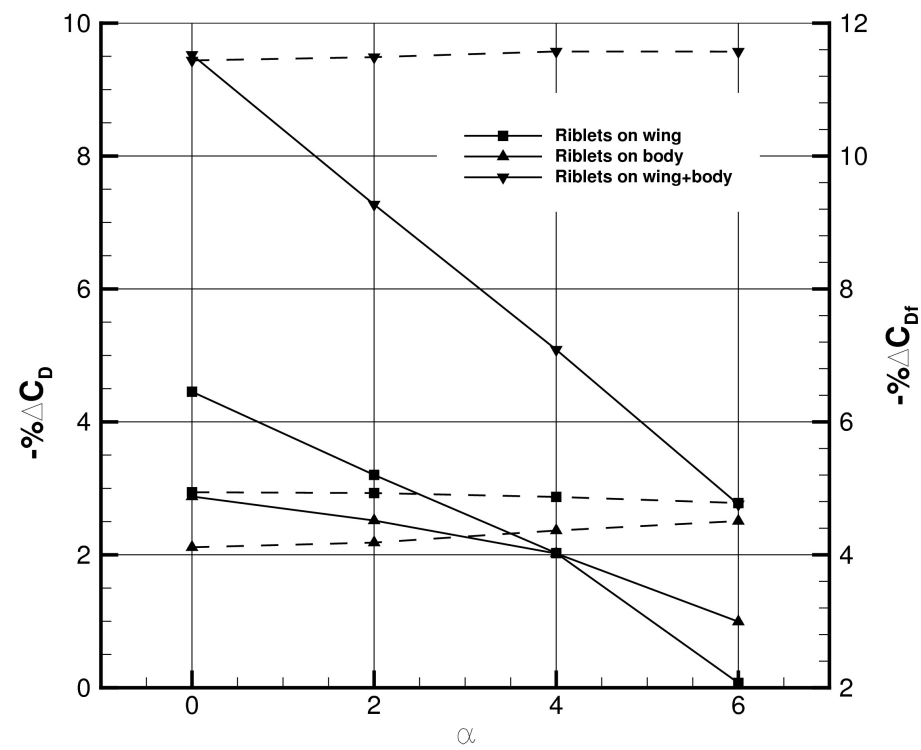

Fig. 10: Wing-body configuration: $\Delta C_{D}$ (percentage gain) by riblets. --: $\Delta C_{D},---: \Delta C_{D f}$

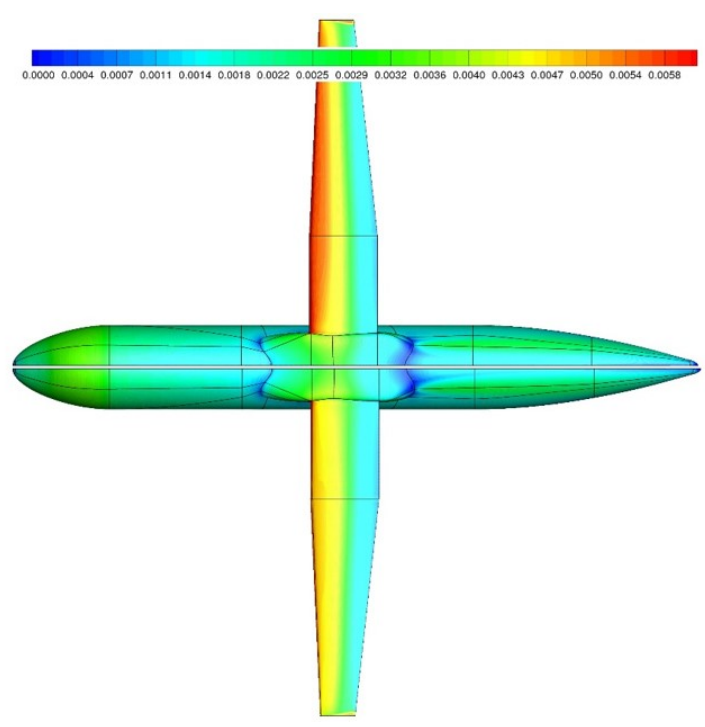

(a) $C_{f}$ distribution on upper surface. Upper plot: Riblets-off; Lower plot: Riblets-on

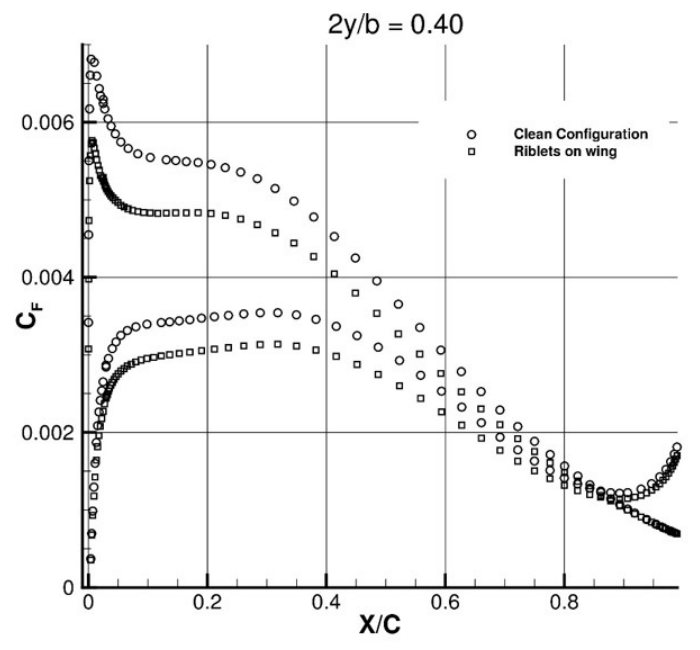

(b) $C_{f}$ at spanwise station $2 y / b=0.40$

Fig. 11: Wing-body configuration: Skin friction coefficient for riblets only on wing

The effect of applying the natural flow technology can be appreciated in figure 14 where the comparison between the "fully turbulent" (with and without riblets) and NLF configurations is shown. The $\Delta C_{D}$ is evaluated with respect to the clean "fully turbulent" configuration. It is possible to note how the order of magnitude of $\Delta C_{D}$ achieved by the NLF technology is the same as for riblets applied on both wing and body on "fully turbulent" configuration (figure 14a). In percentage, the maximum $\Delta C_{D}^{N L F}$ is about $12 \%$ and decreases with the $\alpha$ up to about $2.5 \%$. The gain for the friction component of the drag is about $12 \%$ and keeps constant with the incidence.

The NLF condition presents a large region of turbulent flow and therefore the riblets can be effective also 


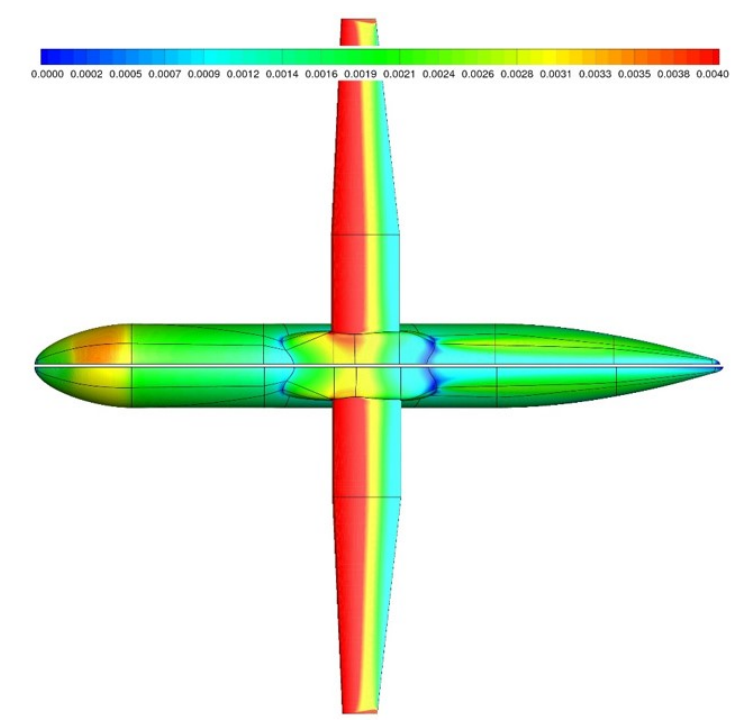

(a) $C_{f}$ distribution on upper surface. Upper plot: Riblets-off; Lower plot: Riblets-on

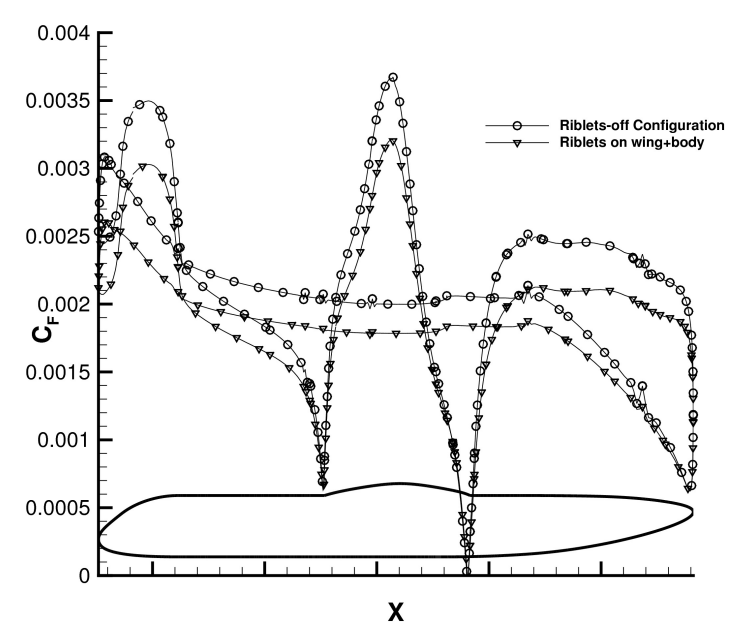

(b) $C_{f}$ at a costant-y section of the body

Fig. 12: Wing-body configuration: Skin friction coefficient for riblets only on body

for such a configuration. The right plot of figure 14 shows the $\Delta C_{D}$ achieved applying the riblets together with the NLF technology. In this plot, the $\Delta C_{D}$ is evaluated with respect to the clean configuration with the NLF assumption. In case of riblets on both body and wing, a further decrease of the total drag coefficient varying with $\alpha$ from about $9 \%$ (3\% body and $6 \%$ wing) to about $3 \%$ (2.5\% body and $0.5 \%$ wing) has been achieved. The friction drag decreases of about $12 \%$ ( $8 \%$ body and $4 \%$ wing).

Finally the contour plot of the friction coefficient over the upper surface of the NLF configuration in riblets-off condition and with the riblets applied on both body and wing is presented in figure 15 . The effect of the riblets is visible on the nose of the body and in the zone of the intersection between the fuselage and the wing. The $C_{f}$ at an outboard station of the wing is presented in the right plot of the figure 15. It is possible to note how the NLF technology presents in the laminar zone with respect to the "fully turbulent" assumption a reduction in friction larger than the riblets. However, the riblets keep their effectiveness in the turbulent region and provide a further gain in $C_{f}$ with respect to the NLF technology.

\section{Climb/Descent condition}

A flow specification of Mach number 0.20 and Reynolds number (based on the chord of the wing) of $1.30 \times 10^{7}$ has been chosen as representative of a climb/descent condition. Only "fully turbulent" conditions have been taken into consideration.

The gain in drag coefficient in climb conditions is shown in figure 16. The "optimum" riblets have been applied on wing, on body, and on all the configuration. Riblets on wing have a similar effect, in term of $\Delta C_{D}$ as the riblets on body. The maximum gain in drag is achieved when riblets are applied on wing and fuselage and results to be about $7 \%$ and decreases with the incidence. The $\Delta C_{D f}$ is about $8 \%$ and is constant with the $\alpha$.

Finally, the contour plot of the friction coefficient over the upper surface is presented in figure 17. Again, the riblets are effective in the front part of the wing with an effect quite constant in the span-wise direction and in the region of the nose of the body and of the wing-body intersection.

\section{Estimate of gain for an operative day}

The Breguet formula for the range

$$
R=\frac{\eta}{g c_{s}} \frac{C_{L}}{C_{D}} \ln \frac{W_{i}}{W_{f}}
$$




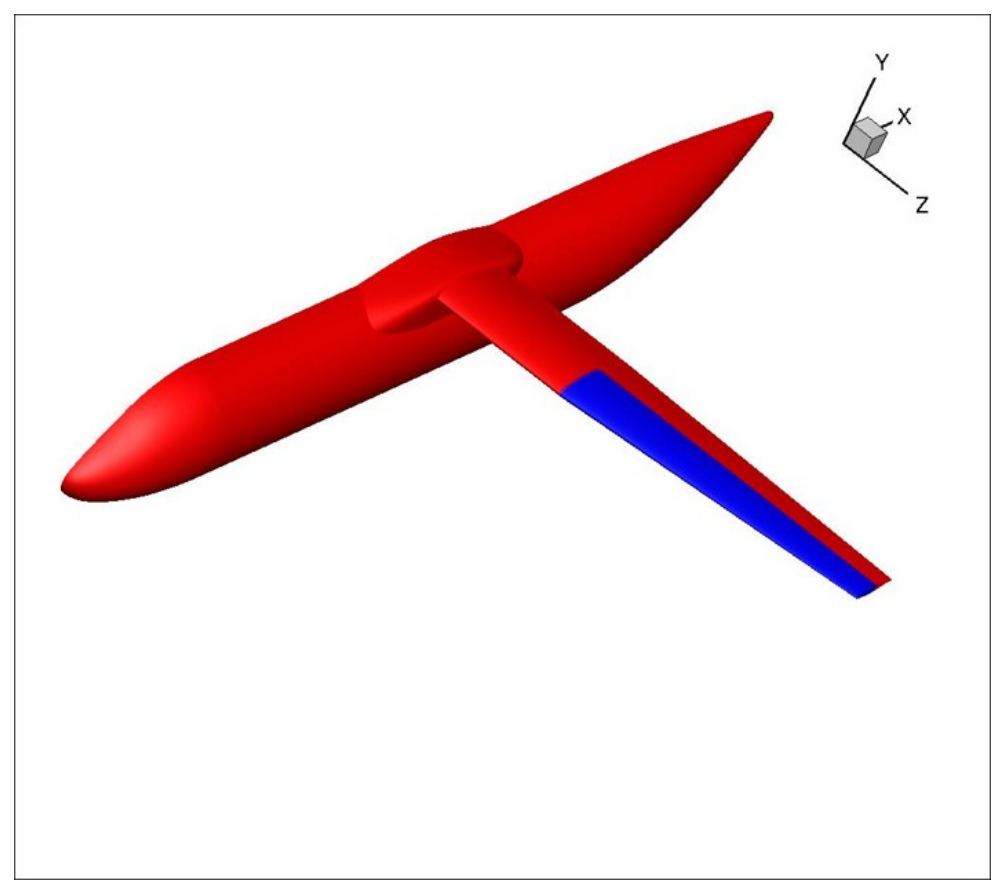

Fig. 13: Wing-body configuration: Numerically reproducing the natural laminar flow technology. blue region: laminar; red region: turbulent

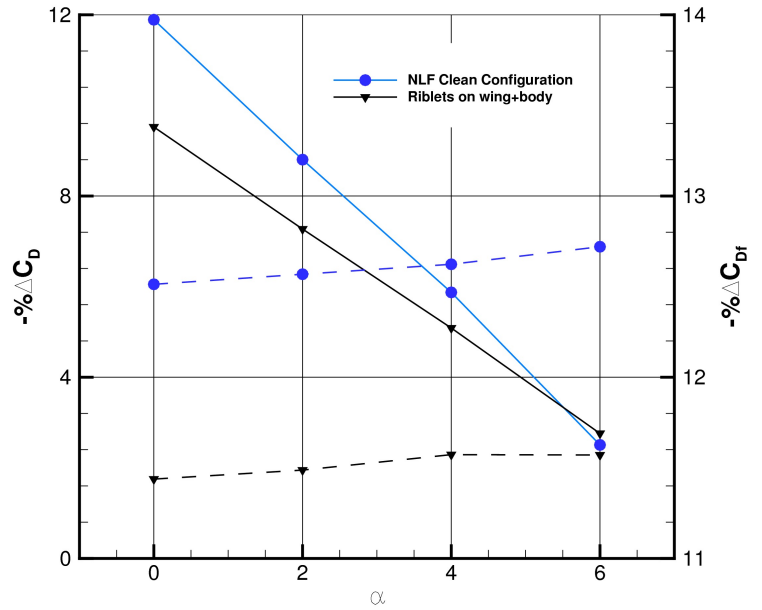

(a) $\Delta C_{D}$ (percentage gain) of NLF configuration with respect to the "fully turbulent" configuration

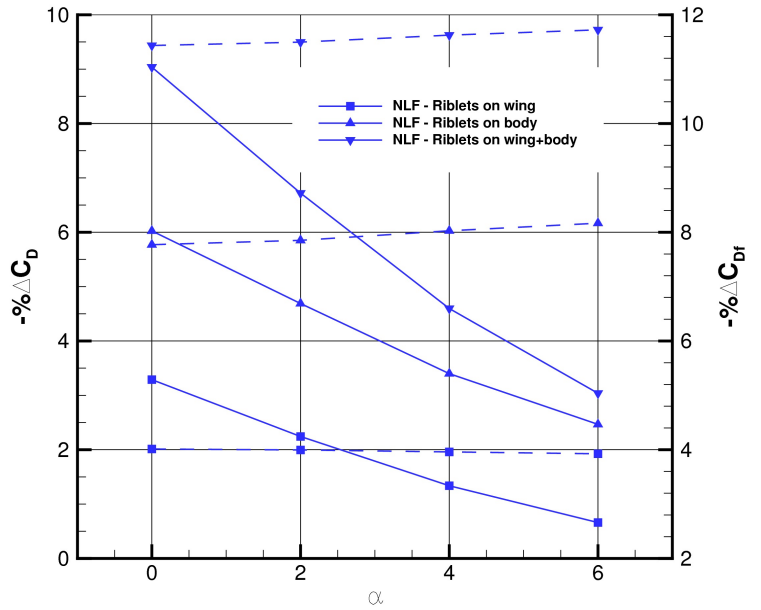

(b) $\Delta C_{D}$ (percentage gain) of riblets on NLF configuration

Fig. 14: Wing-body configuration: NLF technology and riblets. --: $\Delta C_{D},---: \Delta C_{D f}$

is applied with the aerodynamic coefficients retrieved by the drag polars presented in the previous paragraphs. The weight that a new-generation turboprop could save in a mission is evaluated. The analysis is restricted only to the cruise part of a typical mission (figure 18a) with $W_{i}$ the weight at the end of the climb phase and $W_{f}$ the weight at the end of the cruise phase.

A lift coefficient of 0.50 is considered, while the $C_{D}$ is estimated by the values of the drag coefficient of the wing-body configuration $C_{D}^{W B}$. This is obtained by considering the drag breakdown of a typical turboprop-driven aircraft as shown in figure 18b where "other" is represented by interferences, windshield, 


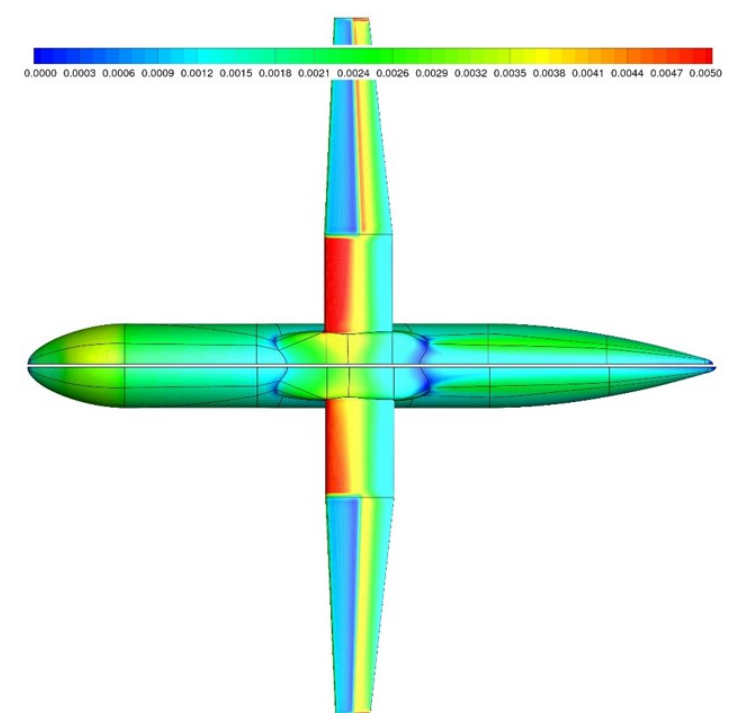

(a) $C_{f}$ distribution over the upper surface of the NLF configuration. Upper: riblets-off; Lower: Riblets-on

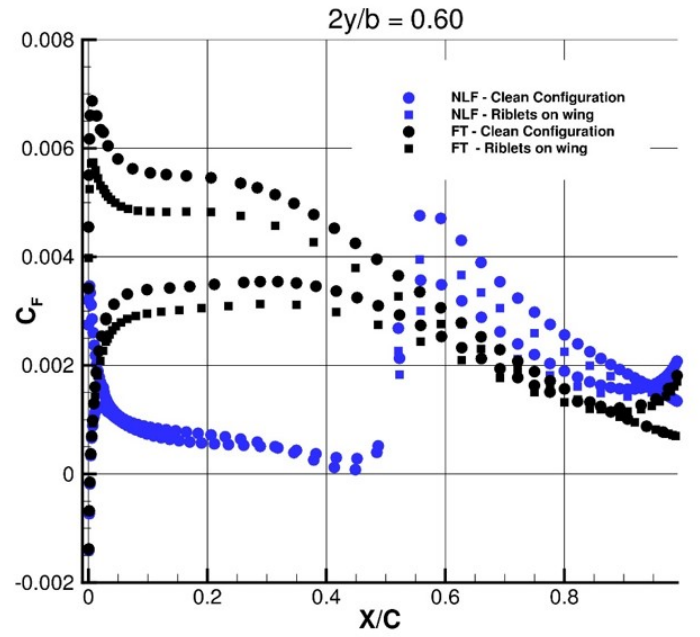

(b) $C_{f}$ at the wing station $2 y / b=0.60$

Fig. 15: Wing-body configuration: Skin friction with NLF technology and riblets

gaps, excrescences and so on. The drag coefficient of the wing-body configuration is

$$
C_{D}^{W B}=C_{D}^{W}+C_{D}^{B}=0.68 * C_{D}
$$

Each contribution to the total drag can be expressed as function of the $C_{D}^{W B}$ exploiting equation 11 as (for example for the horizontal tail):

$$
C_{D}^{H T}=0.04 * C_{D}=\frac{0.04}{0.68} * C_{D}^{W B}=0.059 * C_{D}^{W B}
$$

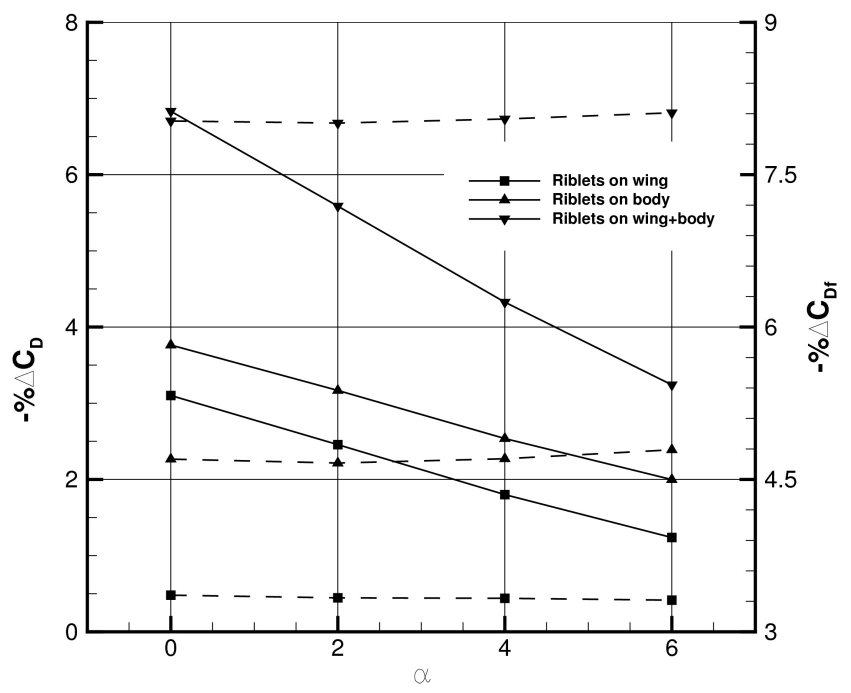

Fig. 16: Wing-body configuration: $\Delta C_{D}$ (percentage gain) in climb conditions. --: $\Delta C_{D},---: \Delta C_{D f}$ 


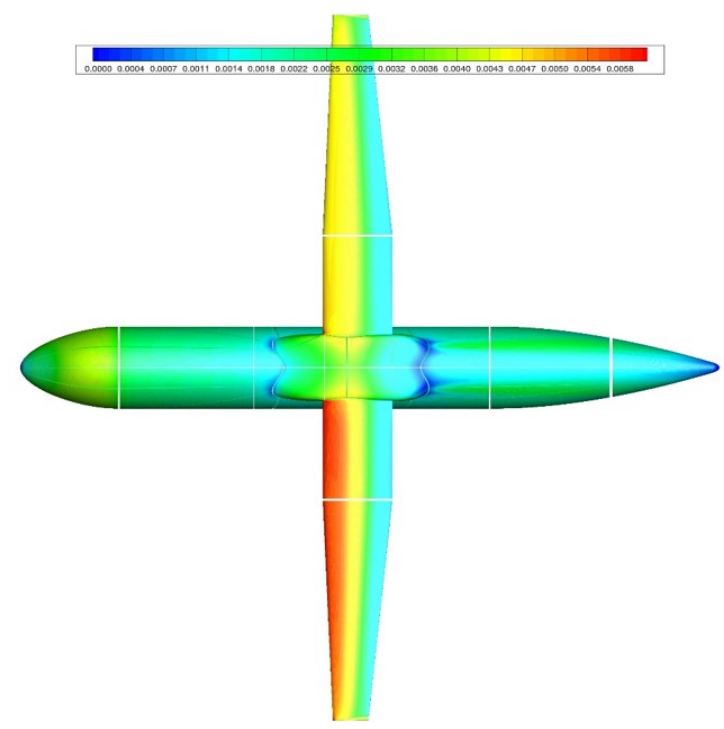

(a) $\alpha=2^{\circ}$. Upper: riblets only on wing; Lower: riblets-off

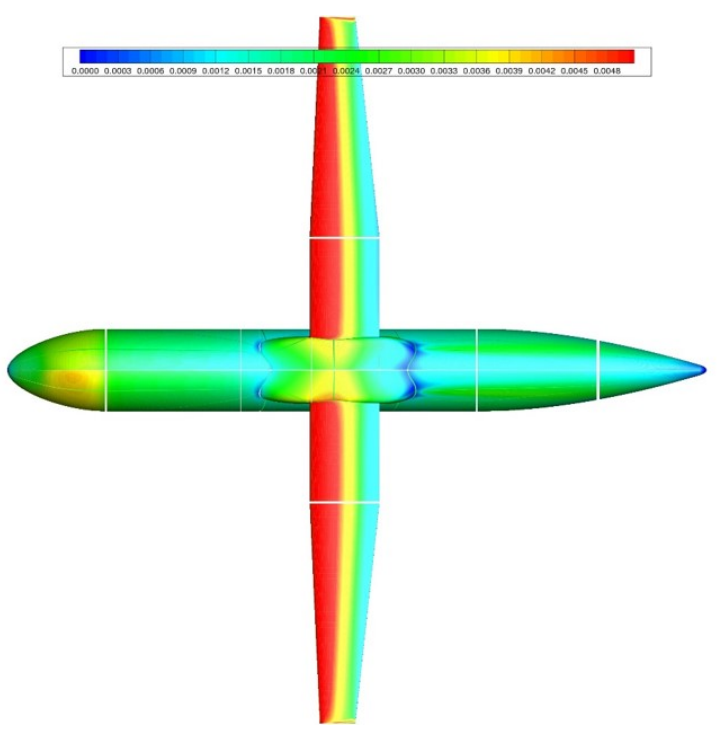

(b) $\alpha=4^{\circ}$. Upper: riblets only on body; Lower: riblets-off

Fig. 17: Wing-body configuration: Skin friction distribution in climb conditions

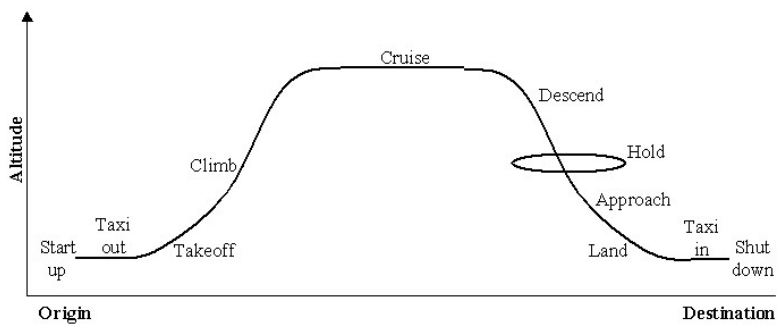

(a) Mission

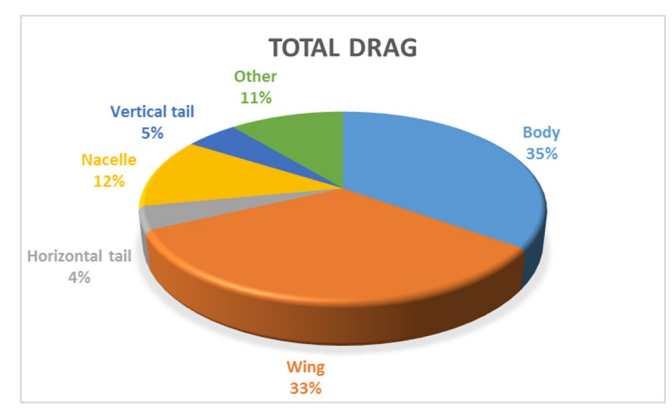

(b) Drag breakdown

Fig. 18: Typical turbopropeller-driven aircraft

and therefore

$$
C_{D}=C_{D}^{W B}+C_{D}^{H T}+C_{D}^{V T}+C_{D}^{N a}+C_{D}^{O t}=C_{D}^{W B}(1+0.059+0.073+0.176+0.162)
$$

The drag coefficient, evaluated by equation 13 by exploiting the drag polars computed for the wingbody configuration, is used in equation 10 where $\eta$ is the efficiency of the engine and $c_{s}$ is the specific fuel consumption. The values considered typical for a turbo-propeller driven aircraft are $\eta=0.85$ and $c_{s}=0.70(l b / h p h)$. The difference in weight $\Delta W$ that can be achieved by riblets and NLF technology has been computed with respect to $W_{f}^{c}$, the weight at the end of the cruise phase of the clean configuration.

The $\Delta W$, in percentage terms, that a turboprop regional aircraft could save in a design mission with a cruise of $900 \mathrm{Nm}$. has been estimated and reported in table 1. The weight that a turboprop regional aircraft

Table 1: Saving of weight for a design mission with cruise phase of $900 \mathrm{Nm}$.

\begin{tabular}{c|c|c|c|c|c|c|} 
& Clean & Riblets wing & Riblets body & Riblets wing and body & NLF & NLF+Riblets wb \\
\hline $100 * \Delta W / W_{f}^{c}$ & 0 & 3.75 & 1.74 & 7.38 & 9.86 & 16.03
\end{tabular}

could save in a typical mission with a cruise of $350 \mathrm{Nm}$. has been estimated and reported in table 2 . 
Table 2: Saving of weight for a typical mission with cruise phase of $350 \mathrm{Nm}$.

\begin{tabular}{c|c|c|c|c|c|c|} 
& Clean & Riblets wing & Riblets body & Riblets wing and body & NLF & NLF+Riblets wb \\
\hline $100 * \Delta W / W_{f}^{c}$ & 0 & 1.6 & 0.74 & 3.15 & 4.20 & 6.82
\end{tabular}

The analysis above reported is partial and suffers from some assumptions especially with regards to the evaluation of the drag coefficient. However, it is possible to state that the NLF technology would allow to save more weight than riblets, about $30 \%$ more. Is is also worth noting that, in terms of saving weight, riblets on wing are more effective (almost two times) than riblets on fuselage.

\section{Conclusions}

The application of the riblets, a promising device for the drag reduction, to a new-generation turboprop configuration has been presented. RANS simulations have been performed by exploiting a proper boundary condition to simulate the effect of the riblets. Drag polars in cruise and climb/descent conditions have been computed.

The wing of the configuration has been designed with the aim to have laminar flow in cruise conditions, and the riblets have been considered also in conjunction with the NLF technology.

The weight that a turbopropeller-driven aircraft could save in the cruise phase of typical mission by applying these drag-reduction devices has been estimated.

NLF technology is shown to be more effective but performance improvement by riblets is comparable and significant.

\section{Ackowledgements}

The research leading to these results has received funding from Clean Sky 2 Joint Undertaking under the European Union's Horizon 2020 research and innovation programme under grant agreement CS2-REGGAM-2014-2015-01.

\section{References}

\footnotetext{
${ }^{1}$ Mele, B. and Tognaccini, R., "Numerical simulation of riblets on airfoils and wings," 50th AIAA Aerospace Sciences Meeting Including the New Horizons Forum and Aerospace Exposition, AIAA 2012-0861, 2012.

${ }^{2}$ Mele, B., Tognaccini, R., and Catalano, P., "Effect of riblets on a complex configuration in transonic conditions." European Drag Reduction and Flow Control Meeting - EDRFCM 2015, Cambridge (UK), 2015.

${ }^{3}$ Mele, B. and Tognaccini, R., "A unified model for riblet simulation in complex flows," XXI Congresso AIMETA, Associazione Italiana di Meccanica Teorica e Applicata, Torino, Sept. 17 -Sept. 202013.

${ }^{4}$ Mele, B., Tognaccini, R., and Catalano, P., "Analyses of non local effects of riblets." XXIII Congresso AIDAA, Associazione Italiana di Aeronautica ed Astronautica, Torino (IT), Nov. 17 -Nov. 192015.

${ }^{5}$ Mele, B., Tognaccini, R., and Catalano, P., "Performance assessment of a transonic wing-body configuration with riblets installed," Journal of Aircraft, Vol. 53, No. 1, 2016, pp. 129-140, doi: http://arc.aiaa.org/doi/abs/10.2514/1.C033220.

${ }^{6}$ Bechert, D., Bruse, M., Hage, W., van der Hoeven, J., and Hoppe, G., "Experiments on Drag-reducing Surfaces and their Optimization with an Adjustable Geometry," Journal of Fluid Mechanics, Vol. 338, 1997, pp. 59-87.

${ }^{7}$ Luchini, P., Manzo, F., and Pozzi, A., "Resistance of Grooved Surface to Parallel Flow and Cross-flow," Journal of Fluid Mechanics, Vol. 228, 1991, pp. 87-109.

${ }^{8}$ Jiménez, J., "Turbulent Flows over Rough Walls," Annual Review Fluid Mechanics, Vol. 36, 2004, pp. $173-196$.

${ }^{9}$ Tani, I., "Drag Reduction by Riblet Viewed as Roughness Problem," Proceedings of the Japan Academy, Vol. 64, 1988, pp. 21-24.

${ }^{10}$ Nikuradse, J., "Laws of Flow in Rough Pipes," Tech. rep., N.A.C.A. TM-1292, Nov. 1950.

${ }^{11}$ Wilcox, D. C., Turbulence Modeling for CFD-II edition, DCW Industries, 1998.

${ }^{12}$ Saffman, P., "A Model for Inhomogeneous Turbulent Flow," Proc. R. Soc. Lond., Vol. A 317, 1970, pp. 417-433.

${ }^{13}$ García-Mayoral, R. and Jiménez, J., "Drag reduction by riblets," Philosophical Transactions of the Royal Society A, Vol. 369, 2011, pp. 1412-1427.

${ }^{14}$ Walsh, M. J., "Riblets," Viscous Drag Reduction in Boundary Layers, Vol. 123 of Progress in Astronautics and Aeronautics, Bushnell \& Efner, 1990, pp. 203-261.

${ }^{15}$ Coustols, E. and Schmitt, V., "Synthesis of Experimental Riblet Studies in Transonic Conditions." Turbulence control by passive means, edited by E. Coustols, 4th European Drag Reduction Meeting, Kluwer Academic, 1990.
} 
${ }^{16}$ Chamorro, L., Arndt, R., and Sotiropoulos, F., "Drag reduction of large wind turbine blades through riblets: evaluation of riblet geometry and application strategies," Renewable Energy, Vol. 50, February 2013, pp. 1095-1105.

${ }^{17}$ Sareen, A., Deters, R., Henry, S., and Selig, M., "Drag reduction using riblet film applied to airfoils for wind turbines," Journal of Solar Energy Engineering, Vol. 136, No. 021007, May 2014, pp. 1-8.

${ }^{18}$ Catalano, P., Mele, B., and Tognaccini, R., "On the implementation of a turbulence model for low Reynolds number flows," Computers and Fluids, Vol. 109, March 2015, pp. 67-71.

${ }^{19}$ Catalano, P., de Rosa, D., Mele, B., Tognaccini, R., and Moens, F., "Influence of riblets and laminar flow control on the performances of a regional aircraft." European Drag Reduction and Flow Control Meeting - EDRFCM 2017, Roma (IT), 2017.

${ }^{20}$ Salah, I., Godard, J., Rodde, A., Moens, F., Andreutti, G., de Rosa, D., Di Muzio, M., Gemma, R., Baldassin, E., Calvi, N., and Averardo, M., "Natural laminar flow transonic wing design applied to future innovative green reegional aircraft," AAAF-CEAS Greener Aviation Conference, March 2014. 